\title{
DEVELOPING A COMPETENCY STANDARD MODEL FOR MEDIA EDUCATION
}

\author{
Gerhard Tulodziecki and Silke Grafe ${ }^{1}$
}

In this article the attempt is made to develop a competency standard model for media education with regard to the discussion about media competence and media education. In doing so the development of a competency model and the formulation of standards is described consequently as a decision making process, which provides different possibilities of structuring, emphasizing and designing. In this article we give reasons for our decisions and present our competency standards model.

The current discussion about school curricula in Germany is - among other things - determined by the goal to develop standards for different subjects in school. These developments were mainly triggered by the dissatisfying results of international large scale assess-

1 Gerhard Tulodziecki is Dr. Phil., Professor for principles of teaching and learning and media education, Faculty of Arts and Humanities, University of Paderborn, Germany

Silke Grafe is Dr. Phil., Professor for theory and design of teaching and learning in the classroom, Faculty of Philosophy and Education, University of Bochum, Germany

Recherches en communication, $\mathrm{n}^{\circ} 33$ (2010). 
ment studies regarding German students' reading, mathematical and scientific literacy skills (see Deutsches PISA-Konsortium, 2001). Such empirical studies as well as the following consequences gave certain subjects - despite or even because of the measured weak achievements - special significance. The risk in concentrating on certain subjects is that other fields of study in school might get less public attention and become less important to teachers and headmasters. Thus it is not surprising that media education has called for standards in its own field (see also the articles in Computer + Unterricht 2006, volume 63). However, the call for standards was not exclusively determined by the concern to fall behind in public and school debates. By the same token media educators in school and educational administration demanded to describe the goals for media education more precisely. Against this background a few drafts for competency models and media education standards have been developed by German-speaking media educators (cf. for instance Moser, 2006; Tulodziecki, 2007; Tulodziecki et al., 2010). Taking those in consideration we outline a concept for a media competency standard model in the following. In doing so, we have the assumption that according to the current situation it is reasonable to develop standards for media competence. However, it is important to consider certain problematic aspects (Tulodziecki \& Grafe, 2005). In particular, educational standards should be understood as a means to support reflection and orientation (and not as an instrument of learning control) and be embedded in the discussion about media competence and education.

\section{Media competence and media education}

\section{as a reference framework for the development of a competency model}

In the German discussion about media competence and media education at least three levels can be distinguished:

The first level is about the frame from which questions or leading ideas of media competence are developed for media education. For example, Baacke (1996) chooses the discussion about communicative competence as a frame and defines media competence as an "ability to use all kinds of media for the communication and action repertoire of people“ (p. 8, own translation). Wagner (2004) adopts a historical perspective and describes media as "tools to learning about and under- 
standing the world" as well as their meaning for cultural and social development. In his opinion media competence aims "at the ability to criticise and analyse and should also include the development of expression skills and of the capacity for experience“" (p. 3, own translation).

Another possibility is to take general leading ideas for education in school as a starting point. In this context media competence is defined as the ability and willingness to deal with media in a skilled, autonomous, creative and socially responsible way (cf. for instance Tulodziecki, 1997, p. 116). Such a competence description is more normative than other psychological competence definitions and therefore corresponds rather to an action-oriented educational perception. However, it still shows clear references to the psycho-educational definition of competence by Weinert (2001, p. 27 f.).

On a second level one has to decide about how to differentiate media competence in a reasonable way and how to structure curricular considerations. Here arise three different ways which are also connected with each other in single concepts.

\section{Structuring according to fields or areas of media competence:}

Baacke (1996, p. 8), for example, distinguishes four fields: media criticism, media knowledge, media use and media creation.

In another approach two fields of activity (distinguishing and using appropriate types of media for a variety of purposes/ creating and disseminating own media messages) and three content areas relevant for action and reflection are described (understanding and evaluating the design of media messages/ becoming aware of and dealing with media influences/ identifying and evaluating conditions of media production and media dissemination), so that a total of five task areas of media education emerge which also contain sub tasks (see below, also Tulodziecki, 1997, p.142 ff.).

\section{Structuring according to dimensions or sub competences:}

Aufenanger (2001, p. 119 f.), for example, defines six dimensions of media competence: he distinguishes a cognitive, a moral, a social, an affective and an aesthetic dimension as well as an action dimension.

\section{Structuring according to different kinds of media:}

Spanhel (1999, p. 173), for example, names various "leading media" for the integration of media education in different forms: pictures for form 5; TV, video and films for form 6; audio media for form 7; newspapers and magazines for form 8; multimedia, CD-Rom, internet for form 9 . 
Apart from these two levels, reflections about media education are on a third level determined by different aspects of teaching media education units or projects in school.

Almost all German media educators favour an action-oriented approach, partly linked with other principles like communication-, situation-, experience-, need- and development- orientation (cf. Tulodziecki, 1997, p. 140 f).

Whereas the first one of the outlined levels describes a possible frame for a competency model, the second level, in particular, contains suggestions on how to structure a competency standard model. The third level rather aims at questions of possible implementations and process standards of media education.

\section{Development of a competency standard model for media education}

When developing a competency standard model for media education, the following questions are important:

- By which competence areas and competence aspects should the competency model be structured?

- Which criteria should be used for differentiating levels?

- For how many levels should standards be developed?

- At which level of abstraction should the standards be formulated?

- Which tasks could be developed to test the standards?

These questions illustrate that the development of a competency standard model is a multistage decision-making process. During this process decisions could be taken according to different reasons.

\section{Definition of fields and aspects of competence for media education}

Taking important aspects of the discussion about media competence and media education into account, the following ways to define fields and aspects of competence emerge (cf. section 1): Fields or areas of media competence, dimensions or sub competences and different kinds of media. Different advantages and problems are connected with each of these three possibilities (cf. Tulodziecki, 2007). We define fields or areas of media competence as subordinate competence fields, being aware of certain problems connected with this decision. In doing so, 
we use the already mentioned five task areas because they have been validated in a research and development project with 15 schools in two federal states and because of their integrative character (cf. Tulodziecki et al., 1998).

In this frame different kinds of media can be chosen to a certain extent as competence aspects. They can be mentioned in an exemplary way in some standard formulations to ease the access to media questions for learners and teachers at school. Dimensions of media competence should be implemented to receive suggestions about criteria for differentiating distinct levels.

Before describing corresponding considerations, we will comment on the chosen fields of competence because of their general importance. The core assumption that underlies the five mentioned task areas (see section 1) is that the different ways of dealing with media can be reduced to two basic forms or characterised by two fundamental ways:

- choosing and making use of existing media, e.g. the reception of newspapers, radio, TV, web sites and other computer-based products for information, learning, entertainment or the use of media as instruments for exchange, cooperation or simulation,

- creating and disseminating own media messages, e.g. creating a newspaper, a video clip or a web site as well as writing an email or creating a blog or a podcast and disseminating their content.

The examples refer to the fact that these two basic forms can appear in separate as well as in a connected manner or that they can overlap. Different levels of media competence are on the one hand determined by knowledge and skills concerning the two basic forms of dealing with media and on the other by knowledge, analysis skills and power of judgement in three content areas:

- design of media messages: from a written text to an animated cartoon, from a headline to a newspaper and to computer menuand window techniques, from a documentary scene to a fictional scene, from an audio play to computer-generated virtual environments,

- media influences: from individual influences on feelings, behaviour and values to the impact of mass and individual communication for public opinion and political views,

- media production and media distribution: from youth protection to personal conditions of a broadcasting company, from economic conditions of media use to economical interests of the computer 
industry, from legal regulations of data privacy and copyright protection to further societal regulations of the media landscape. The structure and reciprocal connections between the basic forms of dealing with media and the content areas is summarized in figure 1.

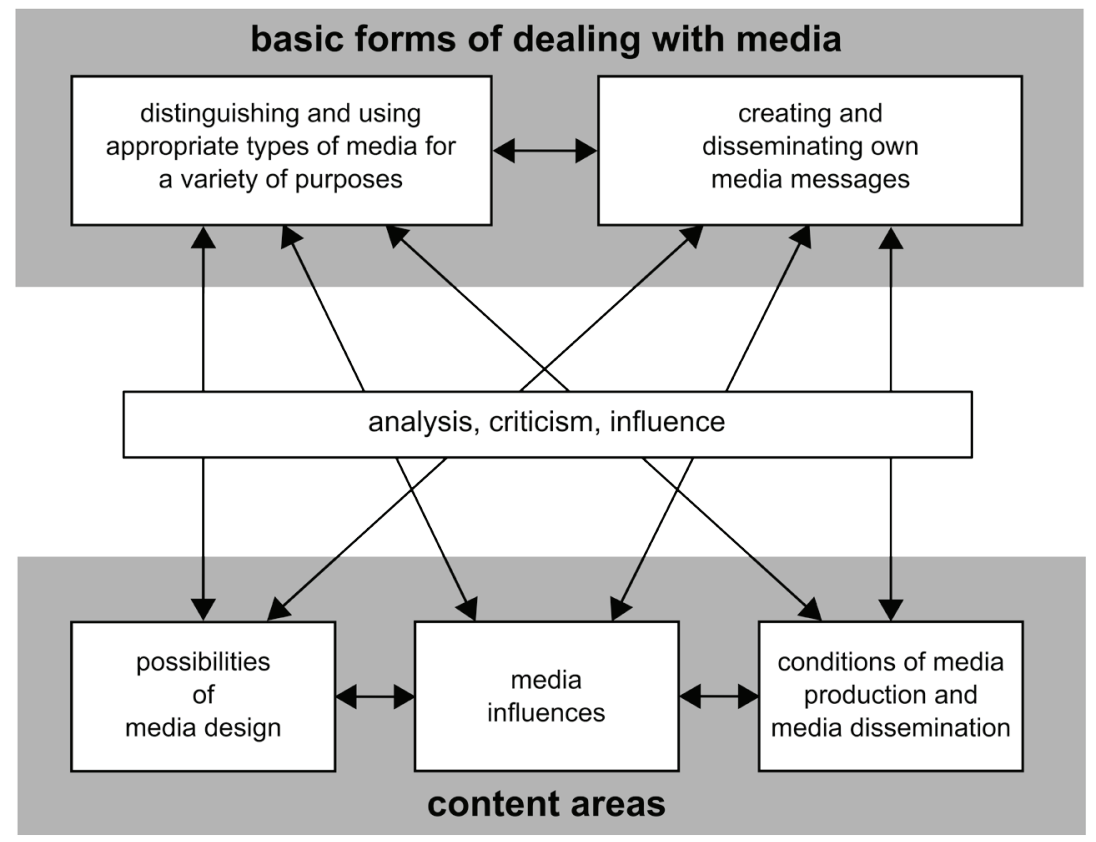

Figure 1: Structure of the concept of media competence

By combining the two basic forms of dealing with media and the three content areas we differentiate between five task areas, which have already been mentioned in section 1 .

In those five task areas knowledge, skills, analysis and criticism should be connected with reference to action. The task areas should not be considered as isolated or separated. They are in fact - as pointed out above - linked in multiple ways. For example, if students create a website in a media education classroom they should at the same time deal with possibilities of website design. Thus they can gain competencies with regard to "creating and disseminating own media messages" as well as in the content area "understanding and evaluating the design of media messages". With these clarifications our competency standard model can be summarized in the following way (see table 1 page 60). 


\section{Determining criteria for distinguishing different levels of media competence}

The reflections about dimensions of media competence refer to the fact that various aspects can play a role in developing a model of media competence. Thus different developmental theories can be used to distinguish different levels of media competence, e.g. psychomotor, affective-motivational, intellectual, psychosocial or moral theories.

For media education three theory complexes are of special significance:

- theories of need and motivation which are concerned with the affective-motivational development,

- theoretical approaches to cognitive complexity which deal with questions of intellectual development,

- theoretical perspectives on social-moral judgment development which aim particularly at the development of social value orientations.

For example, taking the affective-motivational development into account one can - according to Maslow (1981) - assume, that physiological needs, safety needs, the need of love and belonging, the need of esteem and the need of self-actualization play a role in using media. For children in primary school, for example, the need of belonging is assumed to be dominant. Thus it would be inadequate to expect as a standard that children of this age use media in a self-determined way without considering the media use of theirs peers. A self-determined media use can only be achieved on a higher level of the hierarchy of needs.

Concerning the intellectual development one can distinguish between five levels of cognitive complexity:

- "fixed thinking" (in a situation only one option to take action is seen, e.g. only reading yellow press to be informed about certain topics),

- "general-isolated thinking" (other options to action are known, but they are evaluated in an isolated and general way, e.g. general appreciation or depreciation of certain sources of information),

- "specific-differentiating thinking" (reflecting on the advantages and disadvantages of possible ways of action, e.g. giving reasons for media use by referring to apparent advantages in comparison to disadvantages), 


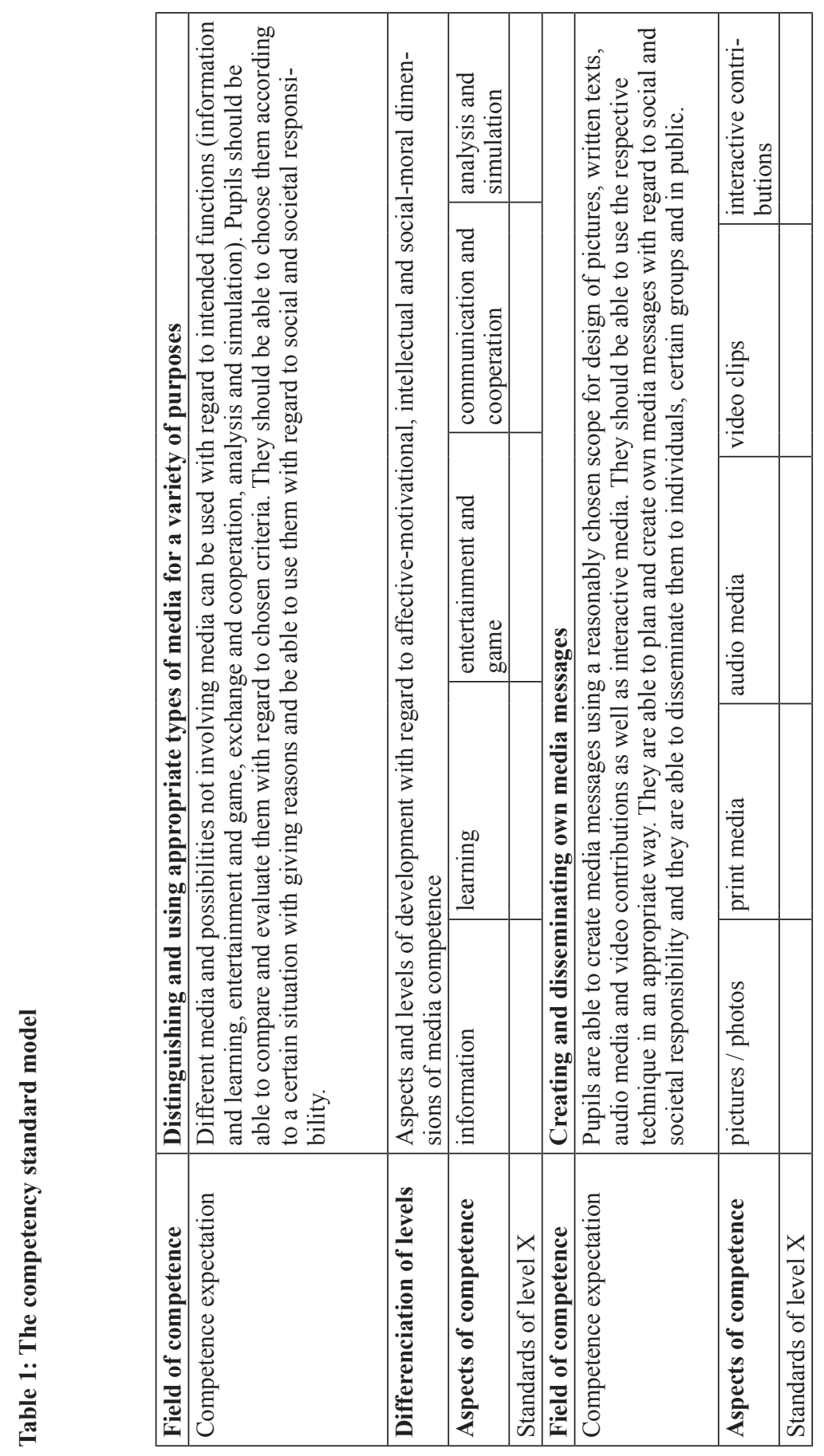




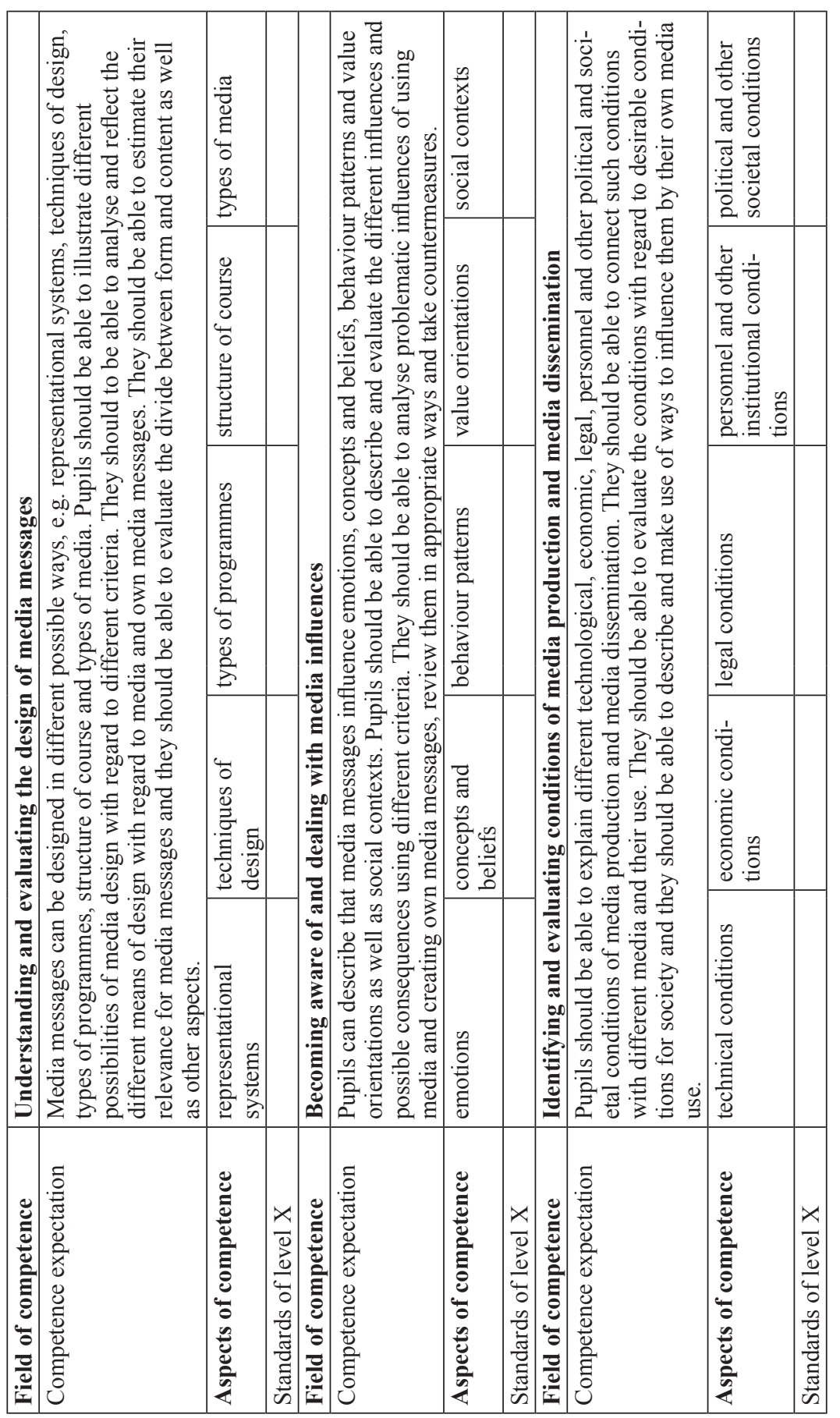


- "systematic-criterion-oriented thinking" (different options for taking action are evaluated according to conscious criteria, e.g. evaluate different media sources according to design, information content and reliability),

- "critical-reflective thinking" (criteria to judge different options for taking option are reflected self-critically, e.g. information content versus the design of a medium).

Against this background, for example, pupils of form 6 can only be expected to name different advantages and disadvantages when evaluating a medium, but a "systematic-criterion-oriented" evaluation would normally be too much to ask for (cf. Tulodziecki, 1997, p. 130 ff.).

With regard to social-moral development five different levels, which are e.g. relevant for media use and media analysis and reflection, can be distinguished, too (cf. Kohlberg, 1977; Gilligan, 1983; Tulodziecki, 1997, p. 135 ff.).

- "egocentric fixation on own needs with avoidance of punishment" (e.g. playing a violent computer game with friends as long as nobody finds out, although the parents forbid to play the game),

- "orientation towards own needs with regard to the interests of others" (e.g. offering the parents to help in the kitchen if that enables to go to the cinema in the evening),

- "orientation towards the expectations of significant others" (e.g. watching a TV-show because friends would be disappointed if one could not talk about it the next day),

- "social contract orientation with conscious acceptance of justified obligations" (to refrain from making, distributing or using unauthorized copies of licensed software, because it would be copyright infringement),

- "individual right orientation and their critical judgement under the claim of human community" (e.g. renunciation of playing an indicated computer game because the human dignity is injured by the representations).

With regard to the stages of development of children and teenagers, media education standards should take into account that pupils in form 4 (end of primary school in Germany) can only be expected to perform at the third level and pupils at secondary schools (form 9 or 
10) can be expected to perform on the fourth level (cf. Kohlberg, 1977; Tulodziecki, 1997, p. 135 ff.).

These considerations show that developmental theories can be used to develop standards according to the development stage of children and adolescents. At the same time one can avoid to develop standards which cannot be reached at a particular age.

\section{Determining the number of levels}

Basically it is possible to formulate standards for all forms at school. However, such a strong focus on standards implies a relatively strong predetermination which could prevent a flexible implementation of media education activities in school. Furthermore it could be under certain conditions negated that the development of competences takes considerable time and cannot be expected within shorter intervals. Against this background we suggest to formulate standards for three levels of media competence: for the end of forms 4, 6 and 9.

The rationales for this suggestion are:

- primary schools end in many German federal states with form 4 and till this age some important aspects of media competence should have been developed,

- at the end of form 6 important basics of media competence are essential in order to realize media education activities in forms 7 and 9 without repeatedly spending time on the basics, and

- that at the end of class 9- which is the graduation class in secondary modern schools in many federal states in Germany - a level should be achieved, that enables the adolescents to act in an adequate, self-determined, creative and socially responsible way in a media-saturated world.

Thus a complete competency standard model (see table 1) should in our opinion contain three levels.

\section{Degree of abstraction}

Standards can be formulated with different degrees of abstraction. In doing so, one has to consider, that formulations of more abstract standards on the one hand will lead to reduced number of standards. But these are more vague with regard to testing and have to be completed by additional indicators if necessary. On the other hand, very concrete 
formulations of educational standards are relatively easy to test but result in considerably long lists.

For our competency standard model we have chosen a level of medium degree of abstraction.

With regard to table 1, the two following standards of the competence area "distinguishing and using appropriate types of media for a variety of purposes" and the competence aspect "entertainment and game" for level 3 (end of form 9) serve as an example:

- To be able to use different criteria in order to compare and evaluate various media offers and non-media possibilities for entertainment and game.

- To be able to choose possibilities for entertainment and game based on the situation and to be able to use them in a responsible way.

One important criterion for the formulation of standards is that it becomes clear how tasks could look like that test the standards, without explaining them in detail.

Finally - when formulating standards - it is important to decide whether the standards should be understood as minimum-, regularor maximum standards. For example, the standards described above are meant to be regular standards. According to them minimum and maybe - maximal standards could be developed. At the same time there is also the possibility to modify the standards according to the specific situations or groups.

\section{Development of tasks for testing standards}

If one wants to test if pupils have reached the expected standards according to the competency standard model described above one can use estimate scales, tests with different tasks, showcase, documentation or process portfolios or a combination of these testing techniques. In all cases self-assessment and/or external assessment are possible.

When using estimate scales, the standards themselves or certain indicators can be used to estimate whether a standard has been reached or not yet. When using a test, suitable tasks must be developed (see below). When working with a portfolio, the pupils can collect and reflect on their own media products as well as other students' work as an outcome of media analysis and production or use (cf. for instance Hauf-Tulodziecki, 2003). Each of these forms have certain advantages 
and disadvantages. Working with scales is a relatively small effort but with uncertainties in its results. Using tests ensures greater objectivity and reliability. But their quality is dependent on the quality of the tasks and the development of high quality tasks is time-consuming process. Developing and evaluating a portfolio is time-consuming, too. But provide insight into the development of competence. However, if the goal is to measure the competence level underlying the standard formulations, further considerations with regard to competency testing and diagnostic tests are necessary (cf. Klieme \& Hartig, 2007, p. 24 ff).

Due to the particular challenge of developing a competency test we finish this article with concluding remarks about criteria for tasks in the sense of our competency standard model. First of all, the solution of a task should naturally indicate whether a certain aspect of the standard has been reached or not. In addition, the tasks should be meaningful for the pupils (i.e. to attract the interest of test participants), they should be situated in meaningful contexts (i.e. linked to pupils' lives) and they should be relevant to their current or future actions. Thereby the answer to a task should contain relevant information about how a teacher can help pupils to achieve their learning goals. For instance, the following everyday situation could be presented to pupils:

Thorsten is an outsider in his class. So he is really happy and agrees when Sebastian, one of the most popular pupils in his class, wants to meet with him one afternoon. When Thorsten tells his parents that he goes to Sebastian's house, they are worried because they know that Sebastian gets banned computer games from his older brother and enjoys playing these. However, Thorsten promises them not to play illegal games. When Thorsten arrives at Sebastian's house, he wants Thorsten to play a new banned computer game. Thorsten hesitates, Sebastian urges him to start playing. How do you think he should react in this situation?

The following questions could be added to the description of this situation:

a) What might be reasons for playing banned computer games for Thorsten? Which might be reasons against it?

b) What would you do if you were in Thorsten's situation? Please explain your opinion.

c) What other possibilities can you think of? What are arguments for and against these possibilities?

A task like this can be used to test the standards described in section 2.4. In terms of a responsible choice and use of media it is an 
important criterion if youth protection is discussed (also critically) as an obligatory rule for society in the argumentation. If this is not the case, the answers would show which kind of support is needed for the pupils to achieve their learning goals in future (cf. Tulodziecki, 1997; Herzig, 1998). Besides tasks like this (in which pupils have to find arguments for a certain decision) there are three other kinds of tasks that are useful to test standards and to promote media education in an action-oriented approach: tasks in which pupils have to solve problems, judge a situation or create a product. These tasks are at the same time a means to initiate support for pupils if necessary (cf. Tulodziecki, 1997, pp. 239-262).

\section{Conclusion}

In this article the development of a competency standard model for media education has been described. Against the background of the discussion about media literacy and media education, five competence fields were defined to establish individual areas of competence. Furthermore, the decision was made to formulate standards with a mean level of abstractions as standards for three levels. The developed competency standard model is the result of a complex decision making process. Principally, different decisions could be taken to structure and design the model. It should be understood as a possible basis for the reflection of media education activities and its conception. In this sense our contribution is meant to initiate further developments, testing and discussion.

\section{References}

Aufenanger, S. (2001). Multimedia und Medienkompetenz - Forderungen an das Bildungssystem. In S. Aufenanger; R. Schulz-Zander \& D. Spanhel, (Éd.), Jahrbuch Medienpädagogik 1. (pp. 109-122). Opladen : Leske + Budrich.

Baacke, D. (1996). Medienkompetenz als Netzwerk. Reichweite und Fokussierung eines Begriffs, der Konjunktur hat. medien praktisch, 20, 4-10.

Gilligan, C. (1983). In a Different Voice. Psychological Theory and Women's Development. $6^{\text {th }}$ ed. Cambridge: Harvard University Press. 
Hauf-Tulodziecki, A. (2003). Das Portfolio Medienkompetenz - Konzept und Umsetzung - erste Erfahrungen - weitere Perspektiven. In O. Vorndran \& D. Schnoor (Éd.), Schulen für die Wissensgesellschaft. (pp. 291-302). Gütersloh : Verlag Bertelsmann Stiftung.

Herzig, B. (1998). Förderung ethischer Urteils- und Orientierungsfähigkeit. Grundlagen und schulische Anwendungen. Münster : Waxmann.

Klieme, E., et al. (2003). Zur Entwicklung nationaler Bildungsstandards. Eine Expertise. Frankfurt a.M.: Deutsches Institut für Internationale Pädagogische Forschung.

Klieme, E. \& Hartig, J. (2007). Kompetenzkonzepte in den Sozialwissenschaften und im erziehungswissenschaftlichen Diskurs. Dans M. Prenzel, I. Gogolin \& H.-H. Krüger (Éd.), Kompetenzdiagnostik. Sonderheft 8 der Zeitschrift für Erziehungswissenschaft. (pp. 11-29). Wiesbaden : VS Verlag für Sozialwissenschaften.

Kohlberg, L. (1977). Kognitive Entwicklung und moralische Erziehung. Politische Didaktik. Vierteljahresschrift für Theorie und Praxis des Unterrichts, 3, 5-19.

Maslow, A.H. (1981). Motivation und Persönlichkeit. Reinbek: Rowohlt.

Moser, H. (2006). Standards für die Medienbildung. Computer + Unterricht, 16, 16-18 et $49-55$.

PISA-Konsortium (2001). PISA 2000. Basiskompetenzen von Schülerinnen und Schülern im internationalen Vergleich. Opladen : Leske + Budrich.

Spanhel, D. (1999). Integrative Medienerziehung in der Hauptschule. Ein Entwicklungsprojekt auf der Grundlage responsiver Evaluation. München : KoPäd.

Tulodziecki, G. (1997). Medien in Erziehung und Bildung. Grundlagen und Beispiele einer handlungs- und entwicklungsorientierten Medienpädagogik. Bad Heilbrunn : Klinkhardt.

Tulodziecki, G. (2007). Was Schülerinnen und Schüler im Medienbereich wissen und können sollen -Kompetenzmodell und Bildungsstandards für die Medienbildung. Medienimpulse. Beiträge zur Medienpädagogik, 15, 24-35.

Tulodziecki, G. \& Grafe, S. (2006). Stellenwert und Kritik von Standards für die Lehrerbildung. Internationale Vergleiche und Einschätzungen zur Situation. journal für lehrerInnenbildung, 6, 34-44.

Tulodziecki, G., Möller, D. \& Doelker, Ch. (1998). Bericht zum Modellversuch „Differenzierte Medienerziehung als Element allgemeiner Bildung. Paderborn : Universität.

Tulodziecki, G., Herzig, B. \& Grafe, S. (2010). Medienbildung in Schule und Unterricht. Bad Heilbrunn/ Stuttgart : Klinkhardt/ UTB.

Wagner, W.-R. (2004). Medienkompetenz revisited. Medien als Werkzeuge der Weltaneignung: ein pädagogisches Programm. München : kopaed.

Weinert, F.E. (2001). Vergleichende Leistungsmessung in Schulen - eine umstrittene Selbstverständlichkeit. Dans F.E. Weinert (Éd.), Leistungsmessungen in Schulen. (pp. 17-31). Weinheim : Beltz. 